\title{
INTERAÇÃO ENTRE OUVINTES E EMISSORAS DE RÁDIO POR MEIO DAS MÍDIAS SOCIAIS: o caso da Região Celeiro [RS]
}

\author{
INTERACTION BETWEEN LISTENERS AND RADIO STATIONS \\ THROUGH SOCIAL MEDIA: the case of the Região Celeiro [RS]
}

\author{
Lidia Paula TRENTIN ${ }^{1}$ \\ Universidade Tuiuti do Paraná | Brasil
}

\begin{abstract}
Resumo
Parte da investigação de doutorado, cujos objetos empíricos são as rádios Província 100.7 FM, Querência 89.7 FM e Difusora AM 1350, localizadas na Região Celeiro do Rio Grande do Sul, a presente pesquisa busca identificar as possibilidades de interação entre público e emissoras tendo em vista as mídias sociais dessas rádios. Para tanto, foi realizada uma análise de conteúdo das redes sociais e aplicativos para smartphone, bem como verificação das possibilidades de interação nos sites das três emissoras. Os resultados demonstram que os sites e aplicativos não oferecem possibilidade de interação, é possível apenas ouvir a programação, para contatar as emissoras é necessário utilizar o WhatsApp, e-mail, ligação telefônica ou redes sociais, principalmente o Facebook, que é a rede que mais gera engajamento dos ouvintes das três emissoras. Quanto a responsividade, nenhuma das rádios reage ou responde aos comentários feitos em suas páginas, entretanto, aqueles relacionados à programação, programas e locutores são mencionados ao vivo.

Palavras-chave

Rádio; Rádio na Internet; Interação; Região Celeiro; Rio Grande do Sul.

\section{Abstract}

Part of the doctoral research, whose empirical objects are the radio stations Província 100.7 FM, Querência 89.7 FM and Difusora AM 1350, located in the Região Celeiro do Rio Grande do Sul, this research seeks to identify the possibilities of interaction between public and broadcasters in view of the social media of these radios. To this end, a content analysis of social networks and smartphone applications was carried out, as well as verification of the possibilities of interaction on the websites of the three broadcasters. The results demonstrate that the sites and applications do not offer the possibility of interaction, it is only possible to listen to the programming, to contact the broadcasters it is necessary to use WhatsApp, e-mail, telephone call or social networks, mainly Facebook, which is the network that more generates engagement from the listeners of the three stations. As for responsiveness, none of the radio stations react or respond to comments made on their pages, however, those related to programming, programs and announcers are mentioned live.

Keywords

Radio; Internet radio; Interaction; Região Celeiro; Rio Grande do Sul.
\end{abstract}

RECEBIDO EM 20 DE MARÇO DE 2020

ACEITO EM 18 DE MAIO DE 2020

${ }_{1}$ Doutoranda em Comunicação e Linguagens na Universidade Tuiuti do Paraná - UTP. Bolsista PROSUP/CAPES. Integrante dos Grupos de Pesquisa: Interações Comunicacionais, Imagens e Culturas Digitais - INCOM e Jornalismo no Século XXI - JOR XXI, da UTP. Contato: lidiapaulatrentin@gmail.com.

João Pessoa - Brasil | ANO 7 VOL.7 N.1 | JAN./JUN. 2020 | p. 342-359 


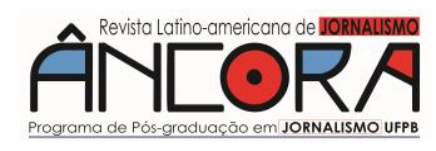

Lidia Paula TRENTIN

\section{Introdução}

pesquisa aqui apresentada faz parte da investigação para a tese
de doutorado da autora. As emissoras foram selecionadas com
base em pesquisas exploratórias e critérios determinados previamente na tese, que levaram à escolha das rádios Província 100.7 FM, de Tenente Portela, Querência 89.7 FM, de Santo Augusto e Difusora AM 1350, de Três Passos, localizadas na Região Celeiro, Noroeste do estado do Rio Grande do Sul, como objetos empíricos.

A escolha por pesquisa em rádio na Região Celeiro se deu pela necessidade de se voltar a estudar esse meio, visto que tem sido, por vezes, deixado de lado, como afirma Kischinhevsky (2012b, p. 418), "com a prevalência dos estudos sobre audiências televisivas e, mais recentemente, sobre o chamado ciberespaço, o privilégio do rádio como objeto (ou, em muitos casos, alvo) foi gradualmente se esvaziando".

Além disso, segundo o Relatório Final da Pesquisa Brasileira de Mídia PBM 2016 (2016b, p. 33), dois terços dos entrevistados afirmaram ouvir rádio, e aproximadamente metade deles ouve todos os dias. O relatório (2016b) também aponta que, assim como no caso do rádio, dois terços dos entrevistados acessam a internet, sendo que o ambiente predominante para esse acesso é o domiciliar e o dispositivo mais utilizado é o celular, superando até mesmo o computador. $\mathrm{O}$ que justifica a pesquisa sobre a utilização de mídias sociais por emissoras de rádio.

Levando essas informações em consideração, o objetivo geral do presente estudo é identificar as possibilidades de interação entre público e emissoras da Região Celeiro tendo em vista as mídias sociais das Rádios mencionadas. Como objetivos específicos têm-se: a) verificar a responsividade das emissoras nas publicações e comentários dos ouvintes nas redes sociais; b) averiguar a frequência de postagens das emissoras nessas redes; e c) 
analisar o conteúdo publicado pelas rádios bem como por seus ouvintes nas redes sociais das emissoras.

Assim, com o intuito de dar embasamento à pesquisa, a seguir serão apresentados pressupostos de autores que discutem o rádio via dial (ou rádio hertziano) e as mudanças que ocorreram a partir do surgimento de novas mídias, bem como com a convergência tecnológica.

\section{Rádio e Convergência Tecnológica}

Apesar de a primeira transmissão oficial de rádio no Brasil ter ocorrido, segundo Ferraretto (2001), em 7 de setembro de 1922, durante a comemoração do Centenário da Independência na Exposição Internacional do Rio de Janeiro, pela Westinghouse, em 1919 o Rádio Clube de Pernambuco já fazia transmissões de rádio, mas sem frequência ou continuidade.

Desde seu início, o rádio foi considerado um meio prestador de serviços à comunidade em que está inserido. Roquette-Pinto assim como Bertold Brecht (2005) viam o rádio como um aparelho de transformação educativa e função pedagógica, principalmente no que se referia à formação cidadã dos ouvintes. Brecht também relacionava a função pedagógica à difusão de valores e ideologias.

Com a Revolução de 1930, explica Ferraretto (2001), o rádio começou a se estruturar como um veículo de comunicação, voltado para a busca de anunciantes e de ouvintes e, entre os anos de 1940 e 1955 ocorreu a era de ouro do rádio no Brasil, quando a programação focava no entretenimento, com radionovelas, programas de humor, de auditório e esportivos (que já existiam no rádio brasileiro desde a década de 1930). O autor (2001) esclarece que, com o envolvimento do Brasil na Segunda Guerra Mundial, o jornalismo radiofônico se fortaleceu, principalmente com o surgimento do "Repórter Esso", cuja estreia se deu às 12 horas e 55 minutos de 28 de agosto de 1941, nas Rádios Nacional, do Rio de Janeiro, e Record, de São Paulo, o informativo era fortemente caracterizado pela sua música e textos de abertura, sendo a sua 


\title{
ANLORA
}

Lidia Paula TRENTIN

maior contribuição para a radiodifusão sonora brasileira o "modelo de texto linear, direto, corrido e sem adjetivações, apresentado em um noticiário ágil e estruturado". Assim, o rádio no Brasil conquista uma audiência massiva (FERRARETTO, 2001, p. 127).

No entanto, com a chegada da televisão no País, a partir de 1955 , os ouvintes passam a desenvolver, também, hábitos de espectadores, assim, o crescimento do setor mantém-se desacelerado frente ao novo meio, pois:

\begin{abstract}
O espetáculo começa a migrar para o novo meio, que, ao acrescentar a ele a imagem, obrigava a busca de um caminho diferente sinalizado por itens até então minoritários dentro da programação - o jornalismo, as transmissões esportivas, o serviço para a população e a música gravada. Para cativar audiências massivas, rádio usaria uma nova tecnologia: o transistor (FERRARETTO, 2001, p. 135).
\end{abstract}

Ou seja, as emissoras adaptaram suas programações e o meio de transmissão para manter o público conquistado ao longo dos anos. O transistor, dispositivo que mudou a história do veículo, diminuiu de tamanho, desconectou dos fios e barateou os aparelhos de rádio, fazendo com que se tornassem mais acessíveis, popularizando o meio.

É nessa época que começa a segmentação do rádio, também com o intuito de manter o público e cativar mais ouvintes. Segundo Gisela Swetlana Ortriwano (1985), algumas emissoras optaram por veicular programações musicais, outras por programações com maior diálogo com o público, isto é, mais "falada", e emissoras que decidiram se especializar em jornalismo.

Com características particulares que o diferencia dos outros meios, como televisão, impresso e internet, o rádio, conforme Ortriwano (1985), tem grande abrangência, pois consegue levar sua programação a lugares que os outros meios não alcançam, tanto por motivos geográficos, quanto econômicos e culturais. Ademais, "a ligação humana com o rádio hertziano se dá através do sentido da audição. Isto é, para escutar rádio, é necessário apenas o sentido biológico de ouvir, nada mais do que isso" (PRATA, 2009, p. 42), isso significa que o ouvinte não precisa ser alfabetizado para ouvir rádio. Brecht (2005, p. 38) explica que, "por mais que o ver fique eliminado, isso não quer dizer que 
não se veja nada, mas, precisamente que se vê tão bem que se vê uma infinidade de coisas tantas 'como se queira'". Essa característica, de utilizar apenas o som, suscita o imaginário do público, que mentaliza o conteúdo de acordo com as suas experiências de vida e opiniões.

Como pode ser observado na década de 1950, com o surgimento da televisão, o rádio é um meio de comunicação que consegue se modificar facilmente. Atualmente a adaptação do meio está acontecendo novamente devido, sobretudo, à internet e à convergência tecnológica, o que significa que o rádio tradicional - hertziano ou via dial -, está passando por um processo de remodelação em virtude dos avanços das tecnologias, com o intuito de manter a audiência que já possui e para atingir novos ouvintes.

Em 1997 Roger Fidler criou o termo "mediamorfose", cujo conceito se refere à adequação dos meios de comunicação tradicionais às novas tecnologias. Prata (2009, p. 79) adaptou o termo para o rádio, o chamando de "radiomorfose". A autora (2009, p. 79-80) explica que ao mesmo tempo que o rádio com presença na internet repete "fórmulas e os conceitos hertzianos, velhos conhecidos do ouvinte, pois é pela repetição que o público se reconhece", ele reconfigura e incorpora outros elementos, "numa mistura que transforma o veículo numa grande constelação de signos sonoros, textuais e imagéticos".

Apesar de o rádio ter sido o primeiro meio a oferecer rapidez e imediatismo na veiculação de informações, atualmente, a internet também disponibiliza conteúdos com agilidade. Entretanto, o rádio continua sendo mais imediato, pois a transmissão de um acontecimento pode se dar via chamada de celular ao vivo durante a programação da emissora, sem necessidade de tratamentos de áudio, texto ou imagem, como ocorre com a internet, televisão e impresso.

A criação de sites pelas emissoras foi uma das principais adaptações que ocorreu no rádio com a convergência tecnológica, neles, segundo Prata 


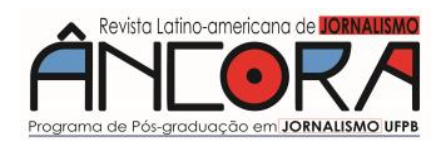

Lidia Paula TRENTIN

(2018, p. 29), as emissoras passaram a "ofertar a transmissão on-line, isto é, um único produto midiático podendo ser acessado simultaneamente no aparelho de rádio e no computador", além de divulgar informações sobre a própria emissora, programação, locutores, publicidades e notícias, como complemento do conteúdo veiculado ao vivo.

Uma nova forma de radiofonia surgiu com a internet, na qual o público pode, além de ouvir as mensagens veiculadas, também encontrá-las em formato de texto, hipertextos, fotos, vídeos, "além do áudio, há toda uma profusão de elementos textuais e imagéticos que ressignificam o velho invento de Marconi" (PRATA, 2009, p. 43). Essa nova forma de radiofonia, que é chamada de "ciber-rádio" por Cebrián Herreros (2008), "rádio hipermidiático" por Lopez (2009) e "rádio expandido" por Marcelo Kischinhevsky (2012).

A maior interação com os ouvintes é uma característica fundamental do "rádio hipermidiático", pois os meios para que isso ocorra foram ampliados e barateados com a internet. Isso se deve, em grande parte, segundo Lopez (2009, p. 05), pelo aumento no número dos aparelhos eletrônicos de última geração no cotidiano dos brasileiros, que tendem a ser multifuncionais, "congregando, por exemplo, acesso à internet, rádio, televisão e telefonia em aparelhos celulares". Assim, o celular tem se tornado "uma importante plataforma para a escuta do rádio. Das pessoas que possuem aparelhos com a funcionalidade, $49 \%$ afirmam utilizá-lo para escutar rádio, número que sobe para 56\% entre os jovens de 12 a 24 anos" (PRATA, 2018, p. 21). Uma grande vantagem do celular é que é um aparelho pequeno, que acumula diversas funções, principalmente o acesso à internet sem fio e pode ser levado a qualquer lugar.

Mas, não basta, somente, as emissoras de rádio estarem presentes na internet, é imprescindível que seus profissionais possuam conhecimentos e estejam preparados para produzir conteúdo multimídia e que sejam criativos nesse processo, que é uma das exigências da internet. $O$ som ainda é ponto 
central do rádio, mas como a internet oferece inúmeras possibilidades, os radialistas devem estar preparados para dar conta delas.

Os ouvintes também acabaram se adaptando com o surgimento constante de novas tecnologias, outros, já nasceram e cresceram em meio a uma infinidade tecnológica, isso faz com que o público não seja mais composto por receptores passivos, mas por pessoas capazes também de produzir conteúdo. E é diante desse perfil diferente de ouvinte que os profissionais do rádio estão. É para produzir informações e programas a esse público que os radialistas devem estar preparados.

Desde a criação do rádio, segundo Lopez (2009), os radialistas vêm adquirindo novas habilidades e responsabilidades, conforme novas funções e atribuições surgiam. De acordo com Prata (2018), no final da década de 1980 as empresas de comunicação - logo também as emissoras de rádio começaram a digitalizar a produção das notícias, o que repercutiu grandemente no trabalho dos profissionais de rádio, uma vez que eles, sem qualquer formação preparatória, tiveram que se tornar profissionais multiplataformas.

Agora há uma pluralidade de vozes no rádio, e, segundo Prata (2018, p. 33), é necessário que os radialistas "saibam lidar com os novos elementos trazidos pela convergência, como o hipertexto, a atualização constante, a multimidialidade e a interação" que são, explica a autora, as palavras-chave do "rádio hipermidiático". Isso significa que o profissional hoje precisa saber produzir conteúdo não só em áudio, mas em forma de texto, fotos, vídeos, infográficos, entre outros, para publicar no site e nas redes sociais da emissora em que trabalha, sempre avaliando e levando em consideração o que o público precisa e o que ele quer saber. É imprescindível também que esse profissional saiba atender as novas formas de interação - mediadas por inovações tecnológicas -, com o público, já que este não é mais um receptor passivo de informações e quer também produzir conteúdo.

João Pessoa - Brasil | ANO 7 VOL.7 N.1 | JAN./JUN. 2020 | p. 342-359 
INTERAÇÃO ENTRE OUVINTES E EMISSORAS DE RÁDIO POR MEIO DAS MÍDIAS SOCIAIS: o caso da Região Celeiro (RS)

Júnior (2006, p. 298), devem ser criadas, pelo próprio pesquisador, categorizações, para "tornar inteligível a massa de dados e sua diversidade".

Assim sendo, foi analisado o conteúdo dos aplicativos e redes sociais (Facebook, Instagram, Twitter e YouTube), bem como a verificação das formas possíveis de comunicação por parte do público nos sites das emissoras de rádio mencionadas, a partir, principalmente, das seguintes categorias: quais as mídias sociais utilizadas por cada uma das emissoras; quais links, nos sites e aplicativos, possibilitam a interação por parte do ouvinte; qual o conteúdo do que é postado nas redes sociais oficiais das rádios; bem como a responsividade, por meio de comentários, dos ouvintes e das próprias emissoras nessas postagens.

\section{Interação por meio das mídias sociais das emissoras de rádio da Região Celeiro}

A pesquisa teve como objetivo identificar as possibilidades de interação entre público e rádios Província 100.7 FM, Querência 89.7 FM e Difusora AM 1350. Além disso, buscou-se verificar a responsividade das emissoras nas publicações e comentários dos ouvintes nas mídias sociais; a frequência de postagens das emissoras nessas redes; bem como o conteúdo publicado nelas.

Quadro 1: Mídias sociais das emissoras

\begin{tabular}{|c|c|c|c|}
\hline Site & RÁDIO PROVÍNCIA FM & $\begin{array}{c}\text { RÁDIO } \\
\text { QUERÊNCIA FM }\end{array}$ & $\begin{array}{c}\text { RÁDIO } \\
\text { DIFUSORA AM }\end{array}$ \\
\hline Recados (site) & provinciafm.com/portal/ & $\begin{array}{c}\text { querenciaonline.co } \\
\text { m }\end{array}$ & rd3.net.br \\
\hline $\begin{array}{c}\text { Popup Player } \\
\text { (site) }\end{array}$ & $\begin{array}{c}\text { Sim, sem possibilidade de } \\
\text { interação }\end{array}$ & $\begin{array}{c}\text { Não, na própria } \\
\text { página } \\
\text { m/contatos/ }\end{array}$ & $\begin{array}{c}\text { https://rd3.net.br/c } \\
\text { ontato }\end{array}$ \\
\hline $\begin{array}{c}\text { "Envie sua } \\
\text { possibilidade de } \\
\text { interação }\end{array}$ \\
\hline $\begin{array}{c}\text { Mural de recadontos (site) } \\
\text { (site) }\end{array}$ & $\begin{array}{c}\text { yucuma.com.br/pedidosdeor } \\
\text { acao }\end{array}$ & Não há & Não há \\
\hline
\end{tabular}

João Pessoa - Brasil | ANO 7 VOL.7 N.1 | JAN./JUN. 2020 | p. 342-359 


\section{AिNLORA}

Lidia Paula TRENTIN

\begin{tabular}{|c|c|c|c|}
\hline Aplicativo & Província FM & Querência Online & $\begin{array}{l}\text { Difusora Três } \\
\text { Passos }\end{array}$ \\
\hline Facebook & Rádio Província FM² & $\begin{array}{l}\text { Rádio Querência } \\
\qquad \mathrm{SA}^{3}\end{array}$ & $\begin{array}{l}\text { Rádio Difusora Três } \\
\text { Passos - RS }\end{array}$ \\
\hline Instagram & radioprovinciafm ${ }^{5}$ & $\begin{array}{c}\text { radio_querencia_89. } \\
7^{6}\end{array}$ & radiodifusora $1350^{7}$ \\
\hline Twitter & Rádio Província FM & Rádio Querência9 ${ }^{9}$ & $\begin{array}{c}\text { Rádio Difusora - } \\
\mathrm{RS}^{10}\end{array}$ \\
\hline WhatsApp & (55) 9 9137-5869 & (55) $99980-0014$ & (55) $3522-1011$ \\
\hline E-mail & ouvinte@provinciafm.com & $\begin{array}{l}\text { ouvinte@querenciao } \\
\text { nline.com }\end{array}$ & $\begin{array}{c}\text { comercial@rd3.net. } \\
\text { br }\end{array}$ \\
\hline YouTube & TV da Província ${ }^{11}$ & $\begin{array}{l}\text { Rádio Querência } \\
\text { Santo Augusto }{ }^{12}\end{array}$ & Difusora $1350^{13}$ \\
\hline Telefone & (55) $3551-1200$ & (55) $3781-1255$ & (55) $3522-1011$ \\
\hline
\end{tabular}

Fonte: a autora (2019)

\section{Rádio Província 100.7 FM}

A programação é transmitida ao vivo por meio do site, ao clicar no play, abre uma nova página, no popup player há apenas a possibilidade de iniciar, parar e alterar o volume da programação, não é possível interagir com a emissora pelo popup. No site os ouvintes encontram links que direcionam para as redes sociais da emissora: Facebook, Twitter e YouTube ${ }^{14}$.

A emissora possui aplicativo para os sistemas operacionais Android e IOS, nele é possível, contanto que haja conexão com a internet, ouvir a programação ao vivo, mas sem possibilidade de interação. Assim como no site, há links para as redes sociais da emissora e para o WhatsApp, abrindo uma

2 Disponível em: <https://www.facebook.com/provinciafm/?ref=hl>.

3 Disponível em: <https://www.facebook.com/querenciaonline/>.

${ }^{4}$ Disponível em: <https://www.facebook.com/difusora.trespassos>.

${ }^{5}$ Disponível em: <https://www.instagram.com/radioprovinciafm/>.

${ }^{6}$ Disponível em: <https://www.instagram.com/radio_querencia_89.7/>.

7 Disponível em: <https://www.instagram.com/radiodifusora1350/>.

${ }^{8}$ Disponível em: <https://twitter.com/Provinciafm>.

${ }^{9}$ Disponível em: <https://twitter.com/radioquerencia>.

${ }^{10}$ Disponível em: <https://twitter.com/Difusora_AM1350>.

${ }_{11}$ Disponível em: <https://www.youtube.com/channel/UCCCDPvJQ5pvfLOnTWxTJmHA>.

12 Disponível em: <https://www.youtube.com/channel/UCkS_EnzZemF8xXRI7yLT6uA/featured>.

${ }^{13}$ Disponível em: <https://www.youtube.com/channel/UCEtkd2LKD8Jba2IvqKjq1g>.

${ }^{14}$ A emissora também possui conta no Instagram, mas não há link no aplicativo para essa rede social. 
conversa com o número da rádio; há também as opções "ligue para nós", "Envie um e-mail" e "Compartilhar o App".

No que se refere a interação dos ouvintes com a emissora por meio das redes sociais, a que gera mais engajamento do público é a página no Facebook, que foi criada em maio de 2014, possui 22.909 curtidas e 24.159 seguidores ${ }^{15}$. A página é atualizada diversas vezes ao dia com vídeos, lives dos locutores, fotos e link das notícias postadas no site. Os ouvintes, além de curtir, compartilhar e comentar as publicações também fazem postagens na página (pedidos de música, lembrança a familiares e amigos, etc.). Os comentários não são respondidos na página, apenas curtidos, mas, aqueles relacionados à programação, programas e locutores são mencionados ao vivo.

O Twitter da emissora foi criado em junho de 2009, segue 694 usuários, possui 586 seguidores e 16,8 mil tweets, era atualizado com frequência até dia 30 de abril de 2019, data em que ocorreu a última postagem. O Instagram da emissora foi atualizado a primeira vez em 26 de setembro de 2018, conta com 165 publicações, 1.576 seguidores e segue 77 pessoas. É pouco atualizado, geralmente com fotos de paisagens ou selfies de um dos locutores, que são curtidas, mas não recebem comentários.

A Rádio possui um canal no YouTube chamado "TV da Província", criado em maio de 2014, com 491 inscritos e 109.576 visualizações, com 11 vídeos e apenas dois comentários que não foram respondidos pela emissora, atualizado pela última vez em 26 de abril de 2019.

\section{Rádio Difusora AM 1350}

A programação também é transmitida ao vivo por meio do site e, ao clicar no play, abre um popup player, em que o ouvinte só pode iniciar, parar e mudar o volume, não há possibilidade de interação. 0 site possui links que direcionam

15 Os dados das redes sociais das três emissoras foram obtidos no dia 08 de novembro de 2019, por este motivo os dados podem variar.

João Pessoa - Brasil | ANO 7 VOL.7 N.1 | JAN./JUN. 2020 | p. 342-359 


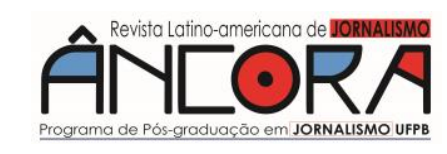

Lidia Paula TRENTIN

para as redes sociais da emissora e para o envio de e-mail e formulário de contato.

A rádio possui aplicativo compatível com os sistemas operacionais Android e IOS, em que o ouvinte pode ouvir a programação ao vivo, sem possibilidade de interagir. Somente há link para o site e para a página no Facebook da emissora. O aplicativo só funciona com a tela do smartphone desligada quando esse está conectado ao carregador, caso contrário, a transmissão para, sendo necessário acessar o site pelo navegador do smartphone e ouvir por ele, caso queira manter a tela apagada. Há também delay em relação à transmissão no popup player do site e ao aplicativo.

Assim como na Rádio Província, a rede social que gera mais engajamento do público é a página no Facebook, que foi criada em novembro de 2012, possui 15.815 curtidas e 16.515 seguidores. A página é atualizada várias vezes ao dia (varia de 10 a 20 postagens em dias de semana e em torno de 5 aos sábados e domingos) com vídeos, lives, fotos e link e título das notícias postadas no site. Os ouvintes, curtem, compartilham e comentam as publicações (o engajamento depende do tipo de postagem, algumas não possuem nenhuma curtida, quanto mais "distante" territorialmente menor o engajamento), quando se trata de lives, fazem comentários com pedidos de música, lembrança a familiares e amigos, etc. Nem todos os locutores mencionam a participação do público. De acordo com o que foi observado na escuta da programação, somente aos domingos os locutores chamam os ouvintes para participar e interagir e mencionam as participações no ar.

O Twitter da emissora foi criado em setembro de 2009, segue 653 usuários, possui 939 seguidores e 16,8 mil tweets, sem atualização desde 0 dia 20 de outubro de 2019. Quanto ao Instagram, foi atualizado a primeira vez em 07 de março de 2018, conta com 142 publicações, 1.680 seguidores e segue 230 pessoas. Também é pouco atualizado, com fotos e vídeos relacionados a acontecimentos em geral que viram notícia e entrevistas 
realizadas pelos locutores. A postagens são curtidas, mas não possuem comentários.

A Rádio possui um canal no YouTube chamado "Difusora 1350", criado em julho de 2018, com apenas 10 inscritos e 12 vídeos, sem interação por parte do público e atualizado pela última vez em 29 de outubro de 2018.

\section{Rádio Querência 89.7 FM}

Por meio do site há a possibilidade de ouvir a programação ao vivo, no entanto, ao clicar em play, não abre nenhum popup player, abre uma nova guia da página inicial da emissora e a transmissão é iniciada e só é possível iniciar, parar e alterar o volume da transmissão. No final da página inicial do site há links que direcionam para as redes sociais da emissora: Facebook, Twitter e YouTube e Instagram.

Assim como as duas outras emissoras a Rádio Querência possui aplicativo para os sistemas operacionais Android e IOS, com as opções de ouvir a programação ao vivo, (sem possibilidade de interação), compartilhá-la via WhatsApp e links para o site (tanto para a página inicial quanto para o formulário de contato da emissora).

A página no Facebook é a rede social que gera mais engajamento do público, foi criada em janeiro de 2011, possui 15.989 curtidas e 16.914. É atualizada diariamente com fotos, lives, vídeos e link com as manchetes das notícias postadas no site. Nem toda postagem gera engajamento. Os ouvintes curtem, compartilham e comentam principalmente o que se refere a esporte e conteúdo policial (assaltos, acidentes, etc.). Os comentários não são respondidos nem curtidos pela emissora na página, mas, quando relacionados à programação, são mencionados ao vivo.

O Twitter foi criado em agosto de 2010, segue 20 usuários e possui 478seguidores, com 416 tweets sem interação, a última atualização ocorreu em 19 de julho de 2019. No que diz respeito ao Instagram da emissora, a primeira publicação se deu em 04 de abril de 2018, possui 423 publicações, 


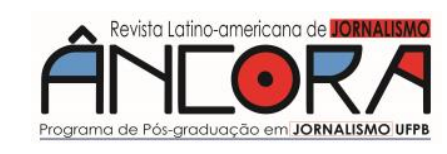

Lidia Paula TRENTIN

2.819 seguidores e segue 489 pessoas. É atualizado com frequência, com imagens promovendo os programas e eventos da emissora, bem como imagens e vídeos de notícias que são postadas no site. Das três emissoras, é a que mais utiliza o Instagram, mesmo assim, suas postagens contam apenas com curtidas, não há comentários.

A Rádio também possui um canal no YouTube chamado "Rádio Querência Santo Augusto", criado em janeiro de 2019, conta com 32 inscritos e 7.653 visualizações, no total de 10 vídeos, atualizado pela última vez em maio de 2019. As postagens não possuem comentários.

\section{Considerações Finais}

A partir da análise das mídias sociais das Rádios Província 100.7 FM, de Tenente Portela, Querência 89.7 FM, de Santo Augusto e Difusora 1350 AM, de Três Passos, com o objetivo de identificar as possibilidades de interação entre público e emissoras da Região Celeiro do Rio Grande do Sul foi possível apreender que, apesar de as emissoras possuírem sites e aplicativos para smartphone, estes não oferecem possibilidade de interação, é apenas possível iniciar, parar e alterar o volume da programação. Para que o público entre em contato com as emissoras é necessário utilizar o WhatsApp, e-mail, ligação telefônica e os perfis e páginas das Rádios nas redes sociais, principalmente no Facebook, que é a rede que mais gera engajamento dos ouvintes das três emissoras.

Os conteúdos publicados nas páginas são, principalmente, vídeos ao vivo gravados por locutores durante a programação, reportagens em forma de vídeo, imagens e manchetes com link direcionando a notícias veiculadas nos sites.

Apesar de as três emissoras estarem presentes no Instagram, Twitter e YouTube, as publicações são bem menos frequentes que nas páginas do Facebook e a interação do público raramente ou nunca acontece. 0 canal no 
YouTube de cada uma das três emissoras, por exemplo, não é atualizado há meses.

No que se refere a responsividade, nenhuma das rádios reage ou responde às postagens e comentários feitos nas publicações de suas páginas, no entanto, aqueles relacionados à programação, programas e locutores são mencionados ao vivo. Essa falta de responsividade pode ocorrer pelo fato de os locutores não darem conta de responder todas as mensagens que recebem, limitando-se, apenas, a mencioná-los no decorrer da programação. Além disso, na Rádio Província, por exemplo, cada comunicador, durante o período de veiculação de seu programa, é responsável também por alimentar, com notícias, o site e as redes sociais da emissora, bem como organizar e divulgar todos os seus patrocinadores, o que toma grande parte do tempo dos locutores fora do ar.

É possível afirmar, com base na pesquisa e nos autores utilizados para fundamentar o estudo, que, principalmente a partir da convergência tecnológica, os locutores assumiram uma postura multitarefa, sobretudo quando se trata de pequenas emissoras de rádio, que contam com um número reduzido de profissionais.

Com o decorrer da pesquisa de doutorado, os motivos pelos quais as emissoras não respondem às participações do público por meio das mídias sociais serão verificados com maior profundidade.

\section{Referências}

BARBEIRO, Heródoto; LIMA, Paulo Rodolfo de. Manual de radiojornalismo: produção, ética e internet. 2 . ed. rev. e atual. Rio de Janeiro: Elsevier: Campus, 2003.

BAUER, M. W. Análise de conteúdo clássica: uma revisão. In: BAUER, M. W.; GASKELL, G. (ed.) Pesquisa qualitativa com texto, imagem e som. 7 ed. Petrópolis, RJ: Vozes, 2008, p. 189-217.

BRECHT, Bertold. Teoria do rádio. In: MEDITSCH, E. (org.). Teorias do rádio: textos e contextos, V. 1, Florianópolis: Insular, 2005, p. 35-45. CEBRIÁN HERREROS, Mariano. La radio en la convergencia multimedia. Barcelona: Gedisa, 2001.

João Pessoa - Brasil | ANO 7 VOL.7 N.1 | JAN./JUN. 2020 | p. 342-359 


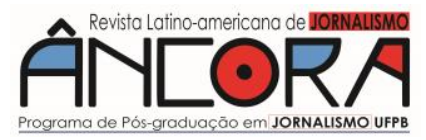

Lidia Paula TRENTIN

CEBRIÁN HERREROS, Mariano. La radio en Internet - de la ciberradio a las redes sociales y la radio móvil. Buenos Aires: La Crujía, 2008.

CEBRIÁN HERREROS, Mariano. 0 rádio no contexto da comunicação multiplataforma. Revista Rádio-Leituras. Ouro Preto. ano II, n. 2, p. 69105. jul. dez. 2011. Disponível em:

$<$ https://periodicos.ufop.br/pp/index.php/radioleituras/article/view/378/345>. Acesso em: 12 fev. 2019.

FERRARETTO, Luiz Artur. Rádio: o veículo, a história e a técnica. 2. ed. Porto Alegre: Sagra Luzzatto, 375 p., 2001.

FIDLER, Roger. Mediamorphosis: understanding new media. Thousand Oaks, California: Pine Forge Press, c1997. xviii, 302 p.

FONSECA JÚNIOR, Wilson Corrêa da. Análise de conteúdo. In: DUARTE, Jorge; BARROS, Antonio. Métodos e Técnicas de Pesquisa em

Comunicação. 2 ed. São Paulo: Atlas, 2006, p.280-304.

HERSCOVITZ, Heloisa Golbspan. Análise de conteúdo em jornalismo. In:

LAGO, Cláudia; BENETTI, Marcia. (orgs). Metodologia de Pesquisa em

Jornalismo. 2 ed. Petrópolis, RJ: Vozes, 2008, p. 123-142.

KAPLÚN, Mario. A natureza do meio: limitações e possibilidades do Rádio. In: MEDITSCH, Eduardo; ZUCULOTO, Valci. (Orgs). Teorias do rádio: textos e contextos. Florianópolis: Insular, 2008.

KISCHINHEVSKY, Marcelo. Radiojornalismo comunitário em mídias sociais e microblogs: circulação de conteúdos publicados no portal RadioTube. Estudos em Jornalismo e Mídia, Florianópolis: Programa de Pós-Graduação em Jornalismo UFSC, v. 9, n. 1, p. 136-148, jan./jun. 2012.

\section{LOPEZ, Debora Cristina. Radiojornalismo e convergência}

tecnológica: uma proposta de classificação. XXXII Congresso Brasileiro de Ciências da Comunicação, Curitiba, 2009.

MEDITISCH, Eduardo; ZUCULOTO, Valci. (Orgs). Teorias do Rádio: textos e contextos. Florianópolis: Insular, 2008.

MEDITISCH, Eduardo; BETTI, Juliana Gobbi. Kaplún e o rádio a serviço da emancipação. In: MEDITSCH, Eduardo; ZUCULOTO, Valci. (Orgs). Teorias do rádio: textos e contextos. Florianópolis: Insular, 2008.

ORTRIWANO, Gisela Swetlana. A informação no rádio: os grupos de poder e a determinação dos conteúdos. V. 3. São Paulo: Summus, 1985. ORTRIWANO, Gisela Swetlana. De Brecht aos (des)caminhos do radiojornalismo. In: MEDITSCH, Eduardo; ZUCULOTO, Valci. (Orgs). Teorias do rádio: textos e contextos. Florianópolis: Insular, 2008. PRATA, Nair. A fidelidade do ouvinte de rádio. Anais do XXV Congresso Brasileiro de Ciências da Comunicação. Salvador. 2002. PRATA, Nair. Webradio: novos gêneros, novas formas de interação. Florianópolis: Insular, 2009.

PRATA, Nair. Rádio, convergência e formação do radialista. In: MEIRELES, Norma; PINHEIRO, Elton Bruno; BARROSO, Lívia Moreira (orgs.). Rádio: estudos contemporâneos. João Pessoa: Editora do CCTA, 2018, p. 20-39. 
RADDATZ, Vera Lúcia Spacil. Ensino de rádio: domínio de ferramentas e formação humana. MEIRELES, Norma; PINHEIRO, Elton Bruno; BARROSO, Lívia Moreira (orgs.). Rádio: estudos contemporâneos. João Pessoa:

Editora do CCTA, 2018.

RÁDIO DIFUSORA AM 1350. Site. Disponível em: <https://rd3.net.br/>. Acesso em: 21 jul. 2019.

RÁDIO DIFUSORA AM 1350. Página no Facebook da Rádio Difusora. Disponível em: <https://www.facebook.com/difusora.trespassos>. Acesso em: 02 ago. 2019.

RÁDIO DIFUSORA AM 1350. Perfil no Instagram da Rádio Difusora.

Disponível em: <https://www.instagram.com/radiodifusora1350/>. Acesso em: 03 ago. 2019.

RÁDIO DIFUSORA AM 1350. Perfil no Twitter da Rádio Difusora.

Disponível em: <https://twitter.com/Difusora_AM1350>. Acesso em: 04 ago. 2019.

RÁDIO DIFUSORA AM 1350. Canal no YouTube Difusora 1350.

Disponível em:

<https://www.youtube.com/channel/UCEtkd2LJKD8Jba2IvqKjq1g>.

Acesso em: 04 ago. 2019.

RÁDIO PROVÍNCIA 100.7 FM. Site. Disponível em:

<http://www.yucuma.com.br/>. Acesso em: 21 jul. 2019.

RÁDIO PROVÍNCIA 100.7 FM. Página no Facebook da Rádio

Província. Disponível em:

<https://www.facebook.com/provinciafm/?ref=hl>. Acesso em: 02 ago. 2019.

RÁDIO PROVÍNCIA 100.7 FM. Perfil no Instagram da Rádio

Província. Disponível em:

<https://www.instagram.com/radioprovinciafm/>. Acesso em: 03 ago. 2019.

RÁDIO PROVÍNCIA 100.7 FM. Perfil no Twitter da Rádio Província. Disponível em: <https://twitter.com/Provinciafm>. Acesso em: 04 ago. 2019.

RÁDIO PROVÍNCIA 100.7 FM. Canal no YouTube TV da Província. Disponível em:

<https://www.youtube.com/channel/UCcCDPvJQ5pvfLOnTWxTJmHA>. Acesso em: 04 ago. 2019.

RÁDIO QUERÊNCIA 89.7 FM. Site. Disponível em:

<https://www.querenciaonline.com/ >. Acesso em: 21 jul. 2019.

RÁDIO QUERÊNCIA 89.7 FM. Página no Facebook da Rádio

Querência. Disponível em:

<https://www.facebook.com/querenciaonline/>.

RÁDIO QUERÊNCIA 89.7 FM. Perfil no Instagram da Rádio

Querência. Disponível em:

João Pessoa - Brasil | ANO 7 VOL.7 N.1 | JAN./JUN. 2020 | p. 342-359 


\section{AिएГОRA \\ Lidia Paula TRENTIN}

<https://www.instagram.com/radio_querencia_89.7/>. Acesso em: 03 ago. 2019.

RÁDIO QUERÊNCIA 89.7 FM. Perfil no Twitter da Rádio Querência. Disponível em: <https://twitter.com/radioquerencia>. Acesso em: 04 ago. 2019.

RÁDIO QUERÊNCIA 89.7 FM. Canal no YouTube Rádio Querência Santo Augusto. Disponível em:

<https://www.youtube.com/channel/UCkS_EnzZemF8xXRI7yLT6uA/featur ed>. Acesso em: 04 ago. 2019. 